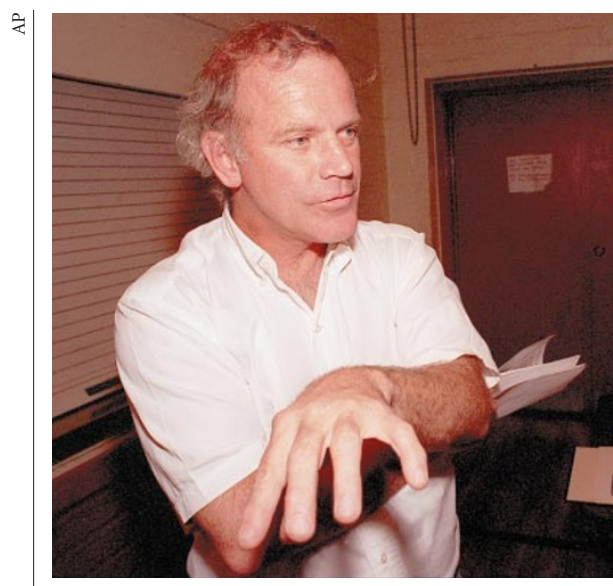

Mullis: as a Nobel laureate "no door in the world will fail to open for you at least once".

chemistry. Beyond that distinction, Mullis stands out for a number of reasons, including behaviour that oscillates between merely eccentric and obnoxious, and utterances that, when not loony, are reminiscent of the child who exclaimed on the emperor's state of undress. He also has an unrestrained penchant for faecal and copulatory terms.

Without the Nobel Prize, proclaimed on a book jacket that pictures Mullis shirtless with surfboard, it is doubtful whether this bizarre pottage would ever have found a publisher. But here it is, an easy weekend read that includes charming recollections of his childhood tinkerings with chemistry, hairraising accounts of trips on LSD and other drugs, disbelief in HIV as the cause of AIDS, and denunciations of those who do not share his respect for astrology. ("There's no proven body of facts in the social sciences", he asserts, "that says human behavior does not contain elements that are related to planetary positions at the time of birth.")

Along the way, Mullis also provides pithy insights into the workings of modern science, observing, for instance: "Probably the most important scientific development of the twentieth century is that economics replaced curiosity as the driving force behind research." And: "When the National Institutes of Health makes an announcement through one of its many spokespeople, who checks out the credibility of that statement? Checks and balances are hard to come by in a scientific establishment that is supported from outside by a populace unskilled in the scientific arts."

Mullis recounts the well-known tale of how the PCR breakthrough occurred to him during a long, night-time drive to his northern California cabin, a girlfriend at his sideone of many girlfriends sprinkled throughout his book, along with the three wives who preceded his current spouse.

Mullis acknowledges the Nobel Prize's power to suspend critical judgement in otherwise sensible people he encounters. "Once you have been given that accolade," he notes, "no door in the world will fail to open for you at least once. It is a free pass for the rest of your life" - even in the case of Mullis, selfdescribed as "a loose cannon on the deck".

His recognition of the "at least once" limitation on doors opening for Nobel laureates is based on experience. Several years ago, Mullis was invited to lecture on PCR to the European Society for Clinical Investigation. According to an indignant report by the outraged president of that organization, Mullis's "only slides (or what he called his art) were photographs he had taken of naked women with colored lights projected upon their bodies". The president added that, in remarks to the audience, Mullis "accused science of being universally corrupt with widespread falsification of data to obtain grants". In a published warning to colleagues, the president declared that his society "will not be inviting Dr Mullis to further meetings".

For those who might be similarly offended by his words and slides, Mullis later announced that for a minimum of $\$ 500$ he would refrain from lecturing at any institution. He explains that he derived the concept of payment for not appearing from his experience with the Glaxo pharmaceutical company, which had acquired Burroughs Wellcome, the manufacturer of AZT. Glaxo, he writes, had offered him a $\$ 1,500$ speaking fee in 1993. When he responded that it was not enough, Mullis reports, Glaxo accepted his demand for $\$ 3,000$ and two first-class air fares. Glaxo then cancelled the invitation, he writes, when it learned that "I would speak about the fact that there is no scientific evidence that HIV is the probable cause of AIDS and that I believed people taking the drug AZT were being poisoned." Whereupon, Mullis continues, he demanded $\$ 6,048$ to compensate for loss of "income from other potential engagements" that he had coupled to the lecture trip. Glaxo promptly paid that amount, he reports, providing the inspiration for a Mullis programme entitled "Have Slides, Will Stay Home. Yes ... But You Must Act Now ... Special Offer”.

Abandoning research, Mullis now writes, consults and lectures about science. The immense wealth generated by PCR eluded him. The Cetus Corporation, where he worked when he invented the PCR technique, paid him only $\$ 10,000$ for the patent, which it later sold to Hoffmann-La Roche for $\$ 300$ million. Neither firm has ever sent him a birthday card, he complains, adding, with characteristic Mullis bravado: "Screw Cetus and the Swiss".

What might have happened if Mullis had captured the riches of PCR? Would he today be dispensing scores of philanthropic millions through the Kary Mullis Foundation? Who would get the money, and for what? Interesting to contemplate; or maybe horrible.

Daniel S. Greenberg is at 3736 Kanawha St. NW,

Washington, DC 20015, USA.

\section{Seeking certainty in an unreliable world}

\section{The Golem at Large: What You Should Know about Technology \\ by Harry Collins and Trevor Pinch \\ Cambridge University Press: 1998. 155 pp. \\ $\mathfrak{E} 12.95, \$ 19.95$}

\section{Barry Barnes}

Of the many impressive texts that use case studies to convey 'what you should know about technology', The Golem at Large is the clearest and simplest. The authors rework existing materials with great care to produce a valuable introduction to their topic that is accessible to anyone. It is, however, necessary to clarify just what that topic is. The case studies presented here are all controversies, about the efficacy of technological artefacts, or the adequacy of technical knowledge or advice. Harry Collins and Trevor Pinch are concerned with the unreliability of what is generally regarded as, and indeed found to be, reliable. They do not focus that concern merely on technology: only three of the seven case studies relate to the working of artefacts; the others describe debates between scientists or technical experts.

The message of the book is that experts are fallible and liable to make mistakes. The claim may seem unremarkable, and is often stressed by experts themselves. But Collins and Pinch insist that a widespread image of scientific knowledge as certain, and technological devices as unconditionally trustworthy, needs to be opposed. Perhaps they are right: memories linger of how BSE, or 'mad cow disease', was said to pose "no conceivable risk" to humans, and many similarly illjudged remarks are quoted here. On the other hand, perhaps they exaggerate the importance of this myth of the certainty of science as a foil for their own arguments. Either way, it is worth asking whether a book designed to attack claims of certainty and omniscience would not be better entitled
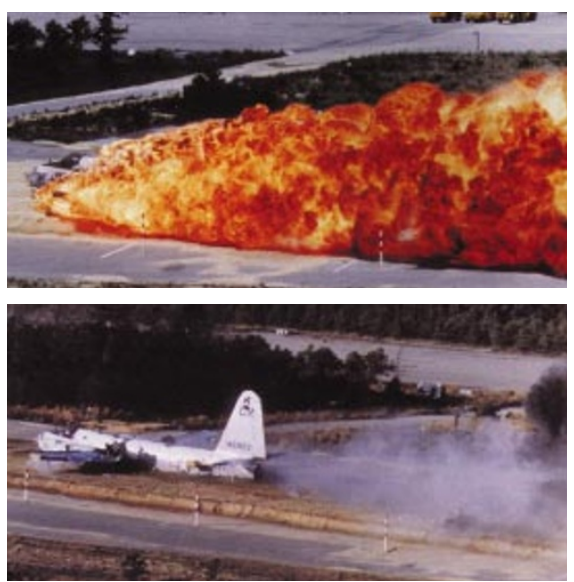

Crash test: technological devices should not be trusted unconditionally, say Collins and Pinch. 
'what you should know about propaganda'.

Collins and Pinch are relativist sociologists who now seem to be widely regarded as among the most radical critics of natural science and scientific expertise, or at least have been denounced as such in the context of the 'science wars'. At first sight, this book confirms the diagnosis: it is 'biased' towards unedifying controversy and technical failure; it includes lengthy discussions of major disasters, such as Chernobyl and the explosion of the US space shuttle; it presents cases in which lay knowledge proves superior to that of experts. But once attention shifts to how the discussion actually proceeds, a very different story suggests itself.

To read these studies is to read what in the last analysis is a powerful defence of experts and expertise. Indeed, I know of no book more sympathetic to them outside the domain of hagiography. The authors stress the formidable difficulty of applying expertise, and the inordinate complexity of the real-world situations in which it is applied, and thereby seek to expose the hindsightbased critical attacks on experts, invariably occasioned when 'things go wrong', as facile, ill-informed and frequently self-serving. It is intriguing to find Collins and Pinch cheerfully using available 'best knowledge' as the basis of their own accounts of 'what really happened', and even lamenting the absence, in one of the situations they describe, of "compelling evidence" of the kind available in astronomy.

There is nothing significantly critical of science, technology or expertise in this book. Indeed, its approach is profoundly conservative. Expertise is going to go wrong, but that is the nature of the beast. A touch of additional reserve and scepticism may be in order, a certain reflectiveness perhaps in the face of expert pronouncements, but nothing else: "We offer no policies". Even the criticism of the myth of scientific certainty is offered only for the greater good of science itself: if we expect too much of science and technology there is the danger of disillusion, of a "flight from reason", a "fall back into a dark age". In the light of all this, it is tempting to suggest that scientists do not always recognize who their friends are, although in the science wars, of course, it might have been that some scientists felt a need for enemies, and that the likes of Collins and Pinch were all they could manage to find.

It is likely that this book, like the authors' similarly designed collection of scientific controversies published five years ago, will be taken up for teaching purposes at an elementary level. The studies should stimulate valuable reflection in this kind of context, and may be used to illustrate far more themes than those discussed explicitly herein. None the less, the very narrow focus of their own discussion might be thought a disadvantage.

It is conceivable that the book will be 'balanced' in some contexts with materials stressing the positive achievements and exemplary reliability of science and technology, and 'balanced' in others with more forthright challenges to their authority and value; certainly, current trends in the mainstream of sociology are in the latter direction. Introductory textbooks, long notorious for making scarcely any mention of science and technology, are now beginning to refer to them, but mainly negatively, in relation to the rise of an alleged risk society and an increasingly threatened environment. But why are Collins and Pinch in practice so very much more positive about technical expertise than is now normal in their discipline? Perhaps part of the answer lies in the many years of close contact they have had with scientists and experts in the course of their substantive research.

Barry Barnes is in the Department of Sociology,

Exeter University, Rennes Drive, Exeter

EX4 4RJ, UK.

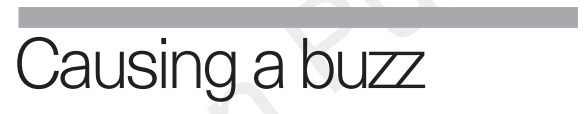

\section{Honeybees of Africa}

by Howard R. Hepburn and S. E. Radloff Springer: 1998. 370 pp. $\{64.50, \$ 109$

\section{Thomas D.Seeley}

The honeybee, Apis mellifera, is the familiar species used for most of the world's beekeeping. It is native to Europe, the Middle East and the whole of Africa, and has been introduced by beekeepers to the Americas, Asia, Australia and the Pacific islands. Although most scientific studies of the honeybee have been conducted in Europe and North America, and have involved the subspecies native to Europe, more than two-thirds of this species' natural distribution area falls in Africa. Across this continent the honeybee inhabits such ecologically diverse settings as lowland rainforests, semi-arid savannahs, steamy coastal swamps and cool mountain ranges.

The smallest and the largest, the blackest and the brightest, and the gentlest and the

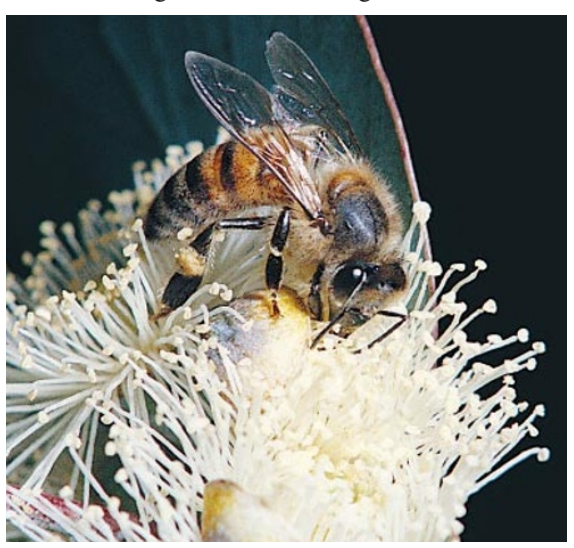

Experimental honeypot: African honeybees can teach us a lot about populations and gene flow. fiercest forms of A. mellifera exist in Africa.

The authors of Honeybees of Africa describe the honeybee scene in Africa as "a magnificent natural experiment", offering a special opportunity to investigate the nature of gene flow, population structure and biological adaptation. This is because these bees have been disturbed by humans only as honey-hunters and fire-starters; more disruptive interventions such as migratory beekeeping and selective breeding are virtually unknown in most of the continent.

The book begins with one of its most significant contributions: a detailed reexamination of the subspecies classification of the honeybees of Africa based on a new multivariate morphometric analysis. By amalgamating their own database at Rhodes University in South Africa with that of the late Friederich Ruttner of the Institut für Bienenkunde in Germany, the authors were able to base their analysis on 18,175 worker bees, representing 1,000 colonies in 291 localities across the continent. The result is a superb presentation, region by region (Maghreb, Nile Valley, East Africa and so on), of the geographical variability and population structure of the African honeybees.

This morphometric analysis, together with genetic studies by others, shows that populations of honeybees thought to be homogeneous and thus defined as subspecies actually show complex geographical variation. A recurrent theme is, therefore, the problem of accommodating natural population variation in a classification scheme. Unfortunately, to name things (such as populations of honeybees) typifies them and leads to typological thinking. In the end, the authors essentially follow Ruttner's classification system of subspecies names, because names are needed to discuss things, but the reader is shown clearly the tremendous variation within the honeybee populations of the continent.

The book's other major contribution is a comprehensive review of the scientific literature. For many topics - including the seasonal migration of colonies, the curious fertility of workers in queenless colonies of A. $m$. capensis, and the diverse predators and parasites of honeybees - the authors provide the best summary available. Often, though, the discussion is necessarily thin, simply for lack of information.

Honeybees of Africa provides biologists with an excellent source of information and challenges. I applaud the authors for thoroughly synthesizing what is known about A. mellifera across the whole of Africa, thereby setting the stage for countless exciting discoveries.

Thomas D. Seeley is in the Section of Neurobiology and Behavior, Cornell University, Mudd Hall, Ithaca, New York 14853, USA. 